\title{
Effects of quercetin on apoptosis, NF-кB and NOS gene expression in renal ischemia/reperfusion injury
}

\author{
M. KENAN KINACI ${ }^{1}$, NILUFER ERKASAP ${ }^{1}$, AYSEGUL KUCUK ${ }^{2}$, TULAY KOKEN $^{3}$ and MURAT TOSUN ${ }^{4}$ \\ ${ }^{1}$ Department of Physiology, Eskisehir Osmangazi University Medical Faculty, Eskisehir; ${ }^{2}$ Department of Physiology, \\ Kutahya Dumlupinar University Medical Faculty, Kutahya; Departments of ${ }^{3}$ Biochemistry, and \\ ${ }^{4}$ Histology and Embryology, Afyon Kocatepe University Medical Faculty, Afyon, Turkey
}

Received August 19, 2011; Accepted October 3, 2011

DOI: $10.3892 /$ etm.2011.382

\begin{abstract}
The aim of this study was to investigate the effects of quercetin on nitric oxide synthase (NOS), nuclear factor- $\kappa \mathrm{B}$ $(\mathrm{NF}-\kappa \mathrm{B})$ and apoptosis in renal ischemia/reperfusion (I/R) injury in rats. A total of 42 Sprague-Dawley rats were divided into three groups. The control, I/R and I/R+quercetin (I/R+Q) groups were treated with quercetin $(50 \mathrm{mg} / \mathrm{kg}$ intraperitoneal) $1 \mathrm{~h}$ prior to the induction of ischemia. Tissue malondialdehyde (MDA) and glutathione (GSH) levels were determined by high-performance liquid chromatography (HPLC). p53, endothelial NOS (eNOS) and $N F-\kappa B$ expression were assessed immunohistochemically, and apoptosis assesment was performed using terminal deoxynucleotidyl transferase dUTP nick end-labeling (TUNEL) assay. The mRNA levels of inducible NOS (iNOS) in renal tissue were determined by realtime polymerase chain reaction (RT-PCR). MDA levels were significantly decreased in the quercetin group compared to the I/R group. However, GSH levels were significantly increased with quercetin treatment in the I/R group. Histological results, the number of apoptotic and p53-positive cells, NF- $\kappa \mathrm{B}$ and eNOS expression levels were significantly decreased in the quercetin treatment group compared to the I/R group. iNOS gene expression increased in the I/R group, but no significant difference was found between the I/R and quercetin treatment groups. Therefore, quercetin not only has antioxidant and antiapoptotic activities, but also has an inhibitory effect on eNOS and $\mathrm{NF}-\kappa \mathrm{B}$ for renal tissue protection during $\mathrm{I} / \mathrm{R}$ injury in rats. Therefore, quercetin may be a promising renoprotective therapeutic agent.
\end{abstract}

Correspondence to: Professor Nilufer Erkasap, Department of Physiology, Eskisehir Osmangazi University Medical Faculty, Eskisehir 26480, Turkey

E-mail: nerkasap@gmail.com

Key words: quercetin, renal ischemia/reperfusion injury, apoptosis, nuclear factor- $\kappa \mathrm{B}$, nitric oxide synthase

\section{Introduction}

Renal ischemia/reperfusion (I/R) injuries are the major causes of acute renal failure and may be involved in the development and progression of certain forms of chronic kidney disease (1). Ischemia is associated with oxidative stress and apoptosis. Oxidative stress is known to be a result of the imbalance between the production of reactive oxygen species (ROS), antioxidants and repair processes (2). Lipid peroxidation, mediated by ROS, is believed to be an important cause of destruction and damage to cell membranes during oxidative stress (3). Tissue levels of malondialdehyde (MDA) are used as indicators of lipid peroxidation $(4,5)$. Glutathione (GSH) also provides major protection in oxidative injury by participating in the cellular system of defense against oxidative damage. Several reports have indicated that various stimuli, such as I/R injury, cause GSH depletion (3). However, ROS also activates nuclear factor $-\kappa \mathrm{B}(\mathrm{NF}-\kappa \mathrm{B}) . \mathrm{NF}-\kappa \mathrm{B}$ regulates the transcription of genes involved in cellular responses to mechanical stress and is required for tissue repair. It is recognized to have a potential role in apoptosis and the adaptive response to stress $(6,7)$.

Apoptosis is a form of programmed cell death, and in this way cells that have been damaged in the organism are removed without harming their environment $(8,9)$. p53 is a tumor suppressor gene that plays an important role in cell cycle control and apoptosis. If p53 is overexpressed, this may cause certain structures to have various abnormalities (10). When tissue is exposed to I/R injury, the DNA in tissue cells may be damaged. If DNA damage is irreparable, p53 activates the apoptotic pathway and directs cell death via apoptosis in order to protect the genome (11).

Nitric oxide (NO) is recognized as an important mediator of physiological and pathological processes of renal I/R injury (12-16). NO is produced by constitutive NO synthases (cNOSs), including endothelial NOS (eNOS), neuronal NOS (nNOS) and inducible NOS (iNOS). Alterations in the expression/activity of the different NOS isoforms have been described in renal I/R (17). However, no study has been found which simultaneously investigates the effects of quercetin on p53, apoptosis, NF- $\kappa \mathrm{B}$ and NOS gene expression in renal I/R injury. Therefore, in the present study, we analyzed the effects of quercetin on p53, apoptosis, eNOS and iNOS expression, as well as $\mathrm{NF}-\kappa \mathrm{B}$ activation, in a renal $\mathrm{I} / \mathrm{R}$ injury rat model. 


\section{Materials and methods}

Animals. Sprague Dawley rats $(\mathrm{n}=42)$ weighing 250-300 g were supplied from the Eskisehir Osmangazi University Experimental Research Center (Turkey). Rats were housed in polycarbonate cages in a temperature-controlled $\left(21 \pm 1^{\circ} \mathrm{C}\right)$ and humidity-controlled (45-55\%) room, which was maintained on a 12/12 reversed light cycle. The rats were fed with a standard rat chow (Oguzlar Yem, Eskisehir, Turkey) and allowed to drink water ad libitum. The present study was approved by the Eskisehir Osmangazi University Institutional Local Animal Care and Use Committee (67/2008). Animals were divided into three groups: group 1, control $(\mathrm{n}=8+6)$; group $2, \mathrm{I} / \mathrm{R}(\mathrm{n}=8+6)$; and group $3, I / R+q u e r c e t i n(I / R+Q)(n=8+6)$. The first 8 rats from each group were selected for histological and biochemical evaluation; the remaining 6 rats were used for real-time polymerase chain reaction (RT-PCR) analyses.

The rats were anesthetized with ketamine $[50 \mathrm{mg} / \mathrm{kg}$ intraperitoneally (i.p.)] and romphun ( $20 \mathrm{mg} / \mathrm{kg}$ i.p.) and placed on a heating pad in order to maintain body temperature. Under aseptic conditions, a midline incision was performed, and a non-traumatic vascular clamp was applied to the left renal pedicle for $2 \mathrm{~h}$ and allowed to reperfuse for $6 \mathrm{~h}$. Quercetin ( $50 \mathrm{mg} / \mathrm{kg}$ i.p.) was administered $1 \mathrm{~h}$ prior to these processes. At the end of the reperfusion period, the left kidneys of the first 8 rats from each group were removed. One-half of the kidney samples were used to evaluate the biochemical parameters, such as MDA and GSH levels, while the other half of the kidney samples were used for immunohistochemical staining. For histological analyses, the samples were maintained in $10 \%$ neutral formalin solution and for biochemical analyses, the samples were kept frozen at $-80^{\circ} \mathrm{C}$ until analysis.

Biochemical determinations (tissue MDA and GSH). The kidney tissues were homogenized in $0.1 \mathrm{M}$ phosphate buffer (pH 7.4) using a homogenizer (Ultra Turrax IKA T18 basic; Wilmington, NC, USA). Homogenized samples were centrifuged at $8,000 \mathrm{rpm}$ for $10 \mathrm{~min}$ at $4^{\circ} \mathrm{C}$, and the supernatant fractions were analyzed for MDA and GSH. MDA and GSH levels were determined by high-performance liquid chromatography (HPLC; Agilent 1100 Series, Munich, Germany) with fluorescence detection using a commercial kit (Chromsystems Diagnostics, Munich, Germany).

Histological determinations. All of the specimens were fixed in $10 \%$ neutral formalin, dehydrated in an increasing alcohol series, cleared in xylene and embedded in paraffin. Numerous $5-\mu \mathrm{m}$ sections were obtained and mounted on both poly-L-lysine-coated slides for immunohistochemistry and classic slides for histochemistry. The slides were stained with hematoxylin and eosin (H\&E) for histochemistry and $\mathrm{p} 53$, eNOS, NF- $\mathrm{kB}$ and the terminal deoxynucleotidyl transferase dUTP nick end-labeling (TUNEL) staining kit were used for immunohistochemistry. The slides were evaluated under a light microscope (E600, Nikon, Japan).

DNA nick end-labeling of tissue sections. For the detection of apoptosis in tissues, a TUNEL-based apoptosis kit (FragEL DNA fragmentation kit; Calbiochem, Darmstadt, Germany) was used. In this method, the sections were first deparaf- finized and rehydrated. They were then permeabilized with proteinase $\mathrm{K}$ and endogen peroxidase, inactivated by $10 \%$ $\mathrm{H}_{2} \mathrm{O}_{2}$. For DNA labeling, Tdt Labeling reaction mix and Tdt Enzyme mixture were used. Following incubation, the reaction was detected with conjugate and diaminobenzidine (DAB) solution in $\mathrm{H}_{2} \mathrm{O}_{2}$ /urea mixture. Methyl green (3\%) was used for counter staining. The slides were then dehydrated and mounted. The TUNEL-positive brown-colored cells were considered to be apoptotic cells, in agreement with the positive control supplied by the manufacturer.

Immunohistochemistry. For the detection of p53, eNOS and NF- $\kappa \mathrm{B}$ expression, immunohistochemistry was applied. For antigen retrieval, microwave treatment was used in $10 \mathrm{mM}$ citrate buffer, $\mathrm{pH} 6.0$ for all samples, and endogenous peroxidase was inactivated by $10 \% \mathrm{H}_{2} \mathrm{O}_{2}$. The specimens were then reacted with primary antibodies. The horseradish peroxidase detection system was used as a secondary antibody and DAB was used for $\mathrm{p} 53$, AEC for eNOS and NF- $\mathrm{KB}$ was used as a chromogen (all chemicals described above were purchased from Lab Vision Corp., Fremont, CA, USA). Mayer's hematoxylin (Sigma, St. Louis, MO, USA) was used for counterstaining. The positively stained cells were counted in image analysis.

Image analysis. p53-, eNOS- and NF-кB-positive and apoptotic cells in 20 different areas in each slide were counted under $\mathrm{x} 20$ objective magnification. For counting, UTHSCSA Image Tool for Windows 3.0 image analysis software was used.

RNA extraction and RT-PCR. The mRNA level of iNOS in relation to the housekeeping gene, glyceraldehyde 3-phosphate dehydrogenase (GAPDH), was determined using RT-PCR with SYBR-Green. Total RNA was extracted from renal tissue by the RNA stabilization reagent (Qiagen, Valencia, CA, USA), according to the manufacturer's instructions, and quantified by measuring the absorbance at $260 \mathrm{~nm}$ (Nanodrop1000; Thermo, Wilmington, DE, USA). Aliquots of $20 \mu \mathrm{l}$ of RNA from each group were applied for the production of complementary DNA (cDNA). The newly synthesized cDNA, stored at $-20^{\circ} \mathrm{C}$, was used for the mRNA assay of the iNOS isoform with RT-PCR. cDNA $(1 \mu \mathrm{l})$ from each group was amplified in $25 \mu$ of reactive mixture with $0.25 X$ SYBR-Green Supermix (Molecular Probes, Invitrogen, Carlsbad, CA, USA). RT-PCR was performed by monitoring in real time the increase in the amount of SYBR-Green using Rotor-Gene 6000 RT-PCR (Corbett Research, Sydney, Australia). The oligonucleotide sequences of the cDNA primers were designed at Gene Research Laboratories, UK. The forward primer for rat iNOS was 5'-CACCACCCTCCTTGTTCAAC-3' and the reverse primer was 5'-CAATCCACAACTCGCTCCAA-3'. Sobajima et al also used GAPDH (housekeeping gene) to normalize iNOS (target gene) data using RT-PCR (18).

RT-PCR thermal cycling conditions were as follows: $5 \mathrm{~min}$ at $65^{\circ} \mathrm{C}, 60 \mathrm{~min}$ at $37^{\circ} \mathrm{C}$ for cDNA synthesis, $15 \mathrm{~min}$ at $95^{\circ} \mathrm{C}$, $15 \mathrm{sec}$ at $95^{\circ} \mathrm{C}, 1 \mathrm{~min}$ at $60^{\circ} \mathrm{C}$ for 50 cycles and $1 \mathrm{~min}$ at $55^{\circ} \mathrm{C}$. RT-PCR data were collected using the Rotor-Gene 6000 detection system. Cycle threshold (CT) values were determined by automated threshold analysis. Primer quality (lack of primer-dimer amplification) was confirmed by melting curve 

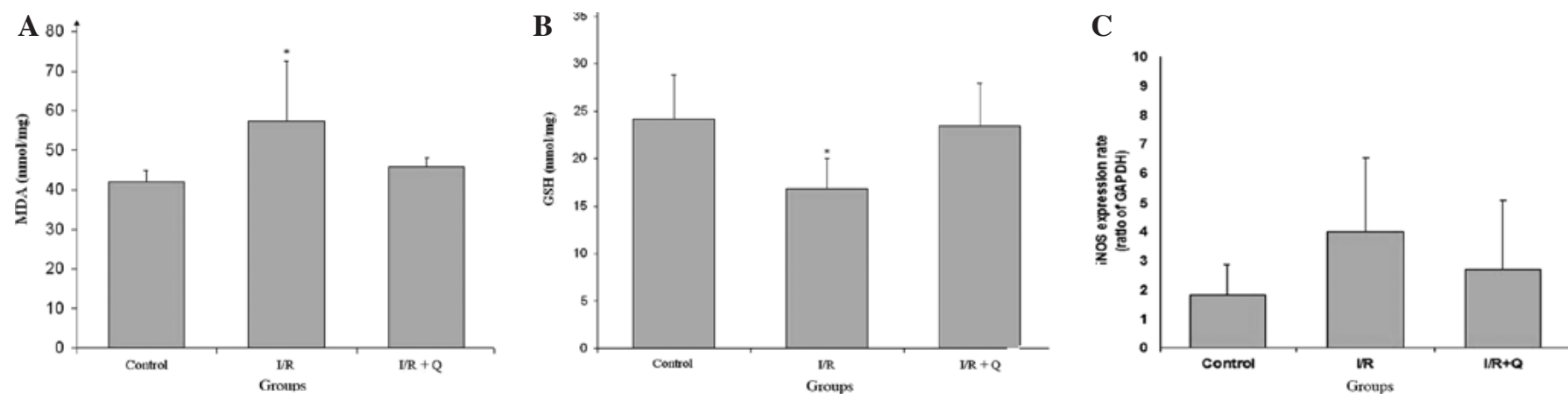

Figure 1. (A) Effect of quercetin on renal tissue MDA levels. " $\mathrm{p}<0.05$; significantly different from the control and the $\mathrm{I} / \mathrm{R}+\mathrm{Q}$ group. (B) Effect of quercetin on renal tissue GSH levels. " $\mathrm{p}<0.05$; significantly different from the control and the I/R+Q group. (C) The iNOS gene expression increased in the I/R group ( $>0.05$ ). MDA, malondialdehyde; GSH, glutathione; iNOS, inducible nitric oxide synthase; GAPDH, glyceraldehyde 3-phosphate dehydrogenase; I/R, ischemia/reperfusion; I/R+Q, I/R+quercetin.

analysis. Relative quantification of the gene expression was performed using the standard curve method, constructed with serial dilutions of control mRNA or RT-PCR amplicons. All experiments were carried out in triplicate. iNOS levels were standardized with GAPDH (ratio iNOS:GAPDH) to account for loading differences. Gene expression levels (mRNA) were reported using the median as a point estimator and the range of values.

Statistical analysis. The statistical Package for Social Sciences (SPSS) version for Windows 10.0 was used to evaluate the data. Results were expressed as the means \pm standard deviation (SD). Rejection of the null hypothesis was set at $\mathrm{p}<0.05$.

Biochemical and RT-PCR parameters were analyzed using one-way ANOVA and the Tukey test for post hoc multiple comparison. Histological parameters were analyzed using the Mann-Whitney U test.

\section{Results}

Biochemical results. The level of MDA was significantly increased in the I/R group when compared to the control and quercetin treatment groups. Quercetin treatment decreased MDA levels, which was significant when compared to the control and $\mathrm{I} / \mathrm{R}+\mathrm{Q}$ treatment groups $(\mathrm{p}<0.05$; Fig. $1 \mathrm{~A})$. While I/R injury decreased GSH levels, quercetin treatment increased GSH levels, which was significant when compared to the other groups (p<0.05; Fig. 1B).

\section{RT-PCR results}

Expression of iNOS in renal tissue. In iNOS, gene expression increased in the $I / R$ group and decreased in the $I / R+Q$ group; however, there was no statistically significant difference in the ratio of iNOS:GAPDH between the I/R and I/R+Q groups (Fig. 1C).

\section{Histological results}

Microscopic determinations. In the control group, H\&E staining of all the structures in the kidney were normal in appearance (Fig. 2A). Edema, vascularization, and partly inflammatory fields, were observed in the $\mathrm{I} / \mathrm{R}$ groups when compared to the control and the quercetin-treated group (Fig. 2B). There were some inflammatory cells and edema in
Table I. H\&E-stained sections of rat kidneys.

\begin{tabular}{lccc}
\hline $\begin{array}{l}\text { Histological } \\
\text { determinations }\end{array}$ & $\begin{array}{c}\text { Control } \\
\text { group }\end{array}$ & I/R group & I/R+Q group \\
\hline Edema & 0 & ++ & + \\
Vascularisation & 0 & +++ & + \\
Infiltration & 0 & ++ & + \\
\hline
\end{tabular}

$\mathrm{I} / \mathrm{R}$, ischemia/reperfusion; I/R+Q, I/R+quercetin.

the quercetin-treated group, however, these fields were smaller and weaker than the inflammatory fields observed in the I/R group (Fig. 2C). H\&E-stained sections of rat kidneys are presented in Table I.

p53 expression. Although there were a few p53-expressing cells in the renal tissue of the control group (Fig. 2D), more p53-expressing cells were detected in the I/R group (Fig. 2E). Conversely, the number of p53-expressing cells in the $\mathrm{I} / \mathrm{R}+\mathrm{Q}$ group (Fig. $2 \mathrm{~F}$ ) was significantly decreased compared to the $\mathrm{I} / \mathrm{R}$ group $(\mathrm{p}=0.001)$.

Apoptosis. The number of apoptotic cells significantly decreased in the $\mathrm{I} / \mathrm{R}+\mathrm{Q}$ group (Fig. 3B) compared to the $\mathrm{I} / \mathrm{R}$ group (Fig. 3A) $(\mathrm{p}=0.016)$. There were no apoptotic cells in the control group.

eNOS expression. In the control group, massive eNOS expression was detected at the corticomedullar junction. This expression may be related to a structurally dense vascular network in this area in normal animals (Fig. 4A). However, little eNOS expression was detected in the medullar cords and cortex. However, in the I/R group many eNOS-expressing cells were observed, particularly in the medullar cords (Fig. 4B). The number of these cells was significantly decreased in the $\mathrm{I} / \mathrm{R}+\mathrm{Q}$ group ( $\mathrm{p}=0.002)$ (Fig. 4C).

$N F-\kappa B$ expression. In the control group, many NF- $\kappa \mathrm{B}$-positive cells were observed in the tissue, particularly at the corticomedullar junction (Fig. 4D). Although this number of cells was increased significantly in the $\mathrm{I} / \mathrm{R}$ group $(\mathrm{p}=0.000)$ (Fig. $4 \mathrm{E})$, in the $I / R+Q$ group the number of these cells was clearly decreased $(\mathrm{p}=0.000)$ (Fig. 4F). 

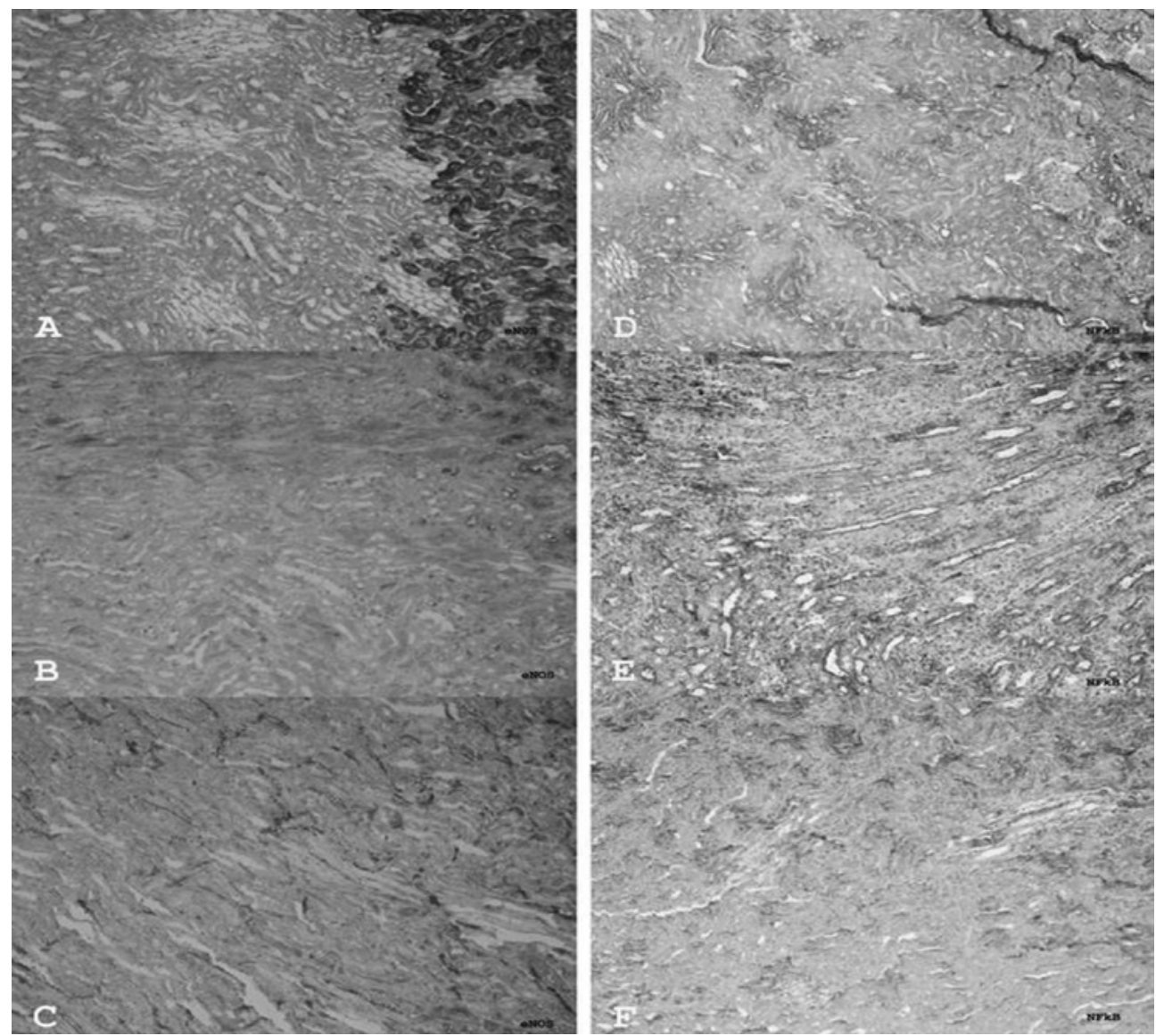

Figure 2. (A) Histological view of renal tissue in the control group (H\&E). (B) Histological view of renal tissue in the I/R group. Evident edema, vasodilatation and mild inflammation (H\&E). (C) Histological view of renal tissue in the $\mathrm{I} / \mathrm{R}+\mathrm{Q}$ group. Decrease in the edema and vasodilatation, and slight inflammation (H\&E). (D) p53-expressing cells (arrows) in renal tissue in the control group. Anti-p53 polyclonal antibody (Lab Vision). (E) p53-expressing cells (arrows) in renal tissue in the I/R group. Anti-p53 polyclonal antibody (Lab Vision). (F) p53-expressing cells (arrows) in renal tissue in the I/R+Q group. Anti-p53 polyclonal antibody (Lab Vision). Magnification, x100. I/R, ischemia/reperfusion; I/R+Q, I/R+quercetin.
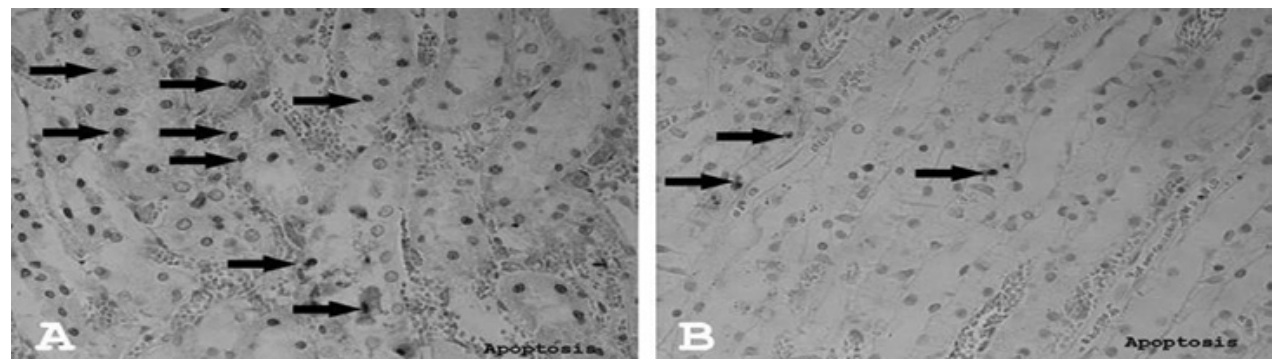

Figure 3. (A) Apoptotic cells (arrows) in renal tissue in the $\mathrm{I} / \mathrm{R}$ group. FragEL (Calbiochem). (B) Apoptotic cells (arrows) in renal tissue in the $\mathrm{I} / \mathrm{R}+\mathrm{Q}$ group Fragel (Calbiochem). Magnification, x200. I/R, ischemia/reperfusion; I/R+Q, I/R+quercetin.

\section{Discussion}

$\mathrm{I} / \mathrm{R}$ induces oxidative stress in the kidneys, which causes the enhancement of the reactive oxygen products and the disappearance of the antioxidant defense system (8). In the present study, I/R injury was created in the renal tissue of rats and it was found that the renal damage created by $I / R$ was significantly decreased by quercetin treatment. In the present study, MDA, which indicates the degree of lipid peroxidation, verifying the oxidative damage in tissue (5) in the I/R-induced renal tissue, significantly increased but then decreased with quercetin therapy. A reduction in the GSH levels was observed in the I/R group, whereas its level was increased by quercetin therapy. As we have observed in our previous studies (19), a return of the increase in the tissue MDA level in the I/R group, and a decrease in the GSH levels back to normal with quercetin treatment, is a result of the antioxidant effect of quercetin.

It is well known that ischemia, together with oxidative stress and reactive oxygen products, arise as a result of oxidative stress (2). ROS activates NF- $\mathrm{kB}$, which is a transcription factor responsible for the production of adhesion molecules and cytokines. A number of clinical and experimental studies 


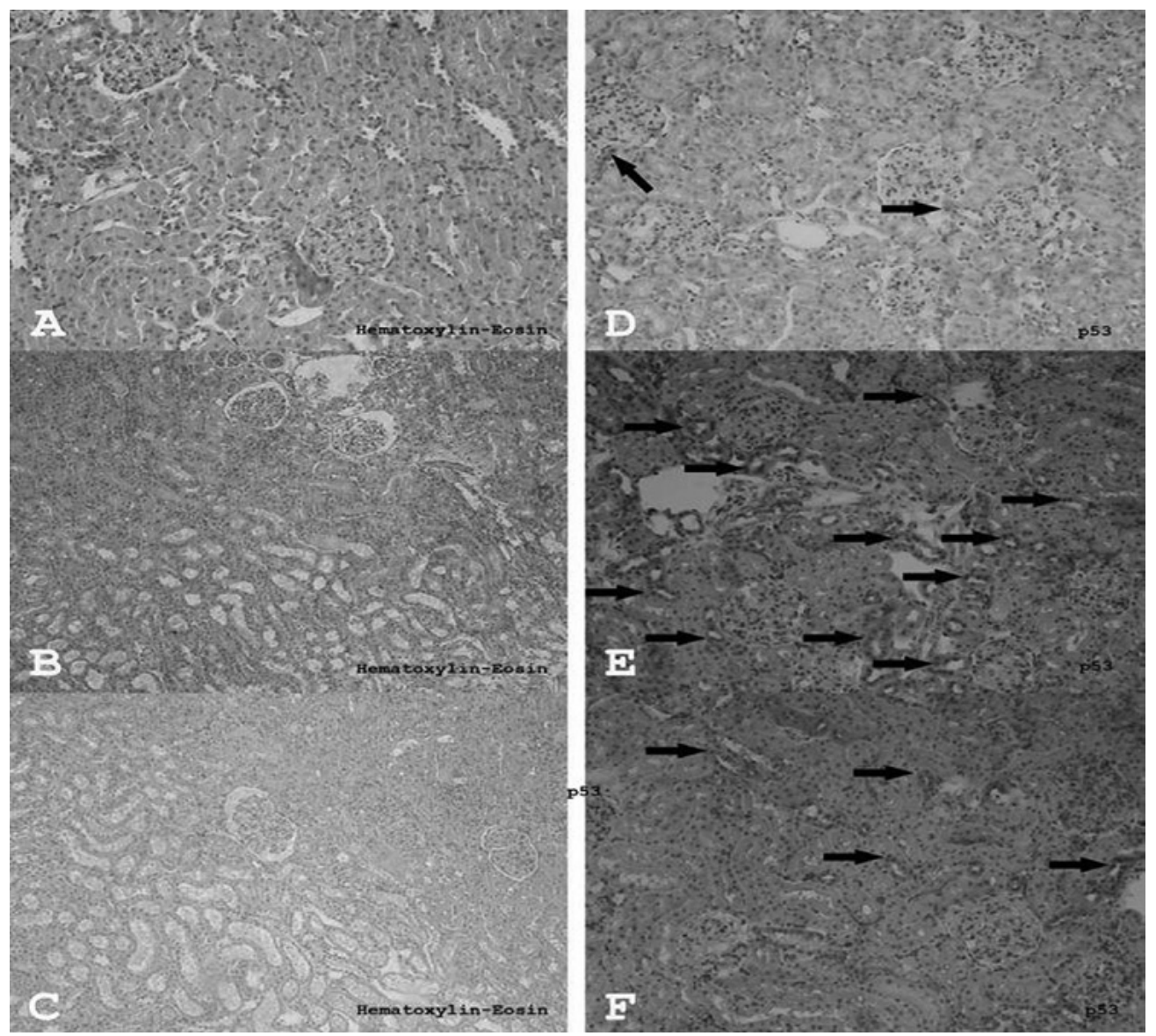

Figure 4. (A) eNOS-expressing cells (arrows) in renal tissue in the control group. Anti-eNOS polyclonal antibody (Lab Vision). (B) eNOS-expressing cells (arrows) in renal tissue in the I/R group. Anti-eNOS polyclonal antibody (Lab Vision). (C) eNOS-expressing cells (arrows) in renal tissue in the I/R+Q group. Anti-eNOS polyclonal antibody (Lab Vision). (D) NF- $\kappa \mathrm{B}$-expressing cells (arrows) in renal tissue in the control group. Anti-NF- $\kappa \mathrm{B}$ polyclonal antibody (Lab Vision). (E) $\mathrm{NF}-\kappa \mathrm{B}$-expressing cells (arrows) in renal tissue in the I/R group. Anti-NF- $\kappa \mathrm{B}$ polyclonal antibody (Lab Vision). (F) NF- $\kappa \mathrm{B}-\mathrm{expressing}$ cells (arrows) in renal tissue in the I/R+Q group. Anti-NF- $\kappa B$ polyclonal antibody (Lab Vision). Magnification, x100. I/R, ischemia/reperfusion; I/R+Q, I/R+quercetin; eNOS, endothelial nitric oxide synthase.

have demonstrated that $\mathrm{NF}-\kappa \mathrm{B}$, a transcription factor, plays a central role in renal pathology (6). Spandou et al reported that renal $\mathrm{I} / \mathrm{R}$ leads to the activation of $\mathrm{NF}-\kappa \mathrm{B}$, which suggests that it may be a marker of injury linked to the pathophysiology of a variety of renal disorders, including I/R, and that its inhibition prevents in vivo cell apoptosis associated with renal I/R injury (20). Therefore, inhibition of the permanent activation of $\mathrm{NF}-\kappa \mathrm{B}$ protects renal tissue from ischemic injury. In the present study, we also detected that $\mathrm{NF}-\kappa \mathrm{B}$ expression was increased in the renal $\mathrm{I} / \mathrm{R}$ group. However, this increase in $\mathrm{NF}-\kappa \mathrm{B}$ expression decreased with quercetin treatment, and this demonstrates that quercetin may act like $\mathrm{NF}-\kappa \mathrm{B}$ inhibitor.

The results of the histological examination revealed that, upon overall tissue evaluation, significant edema, vascularization and patchy infiltration areas formed by the inflammatory cells were detected in the I/R group compared to the quercetin treatment and control groups. In addition, a decreased number of apoptotic cells was observed in the quercetin group when compared to the $I / R$ group. It is known that during renal $I / R$ injury, apoptosis is a very important contributor to kidney damage. While evaluating experimentally created I/R, Vinas et al demonstrated that the cells died of apoptosis or necrosis according to the severity of the injury, due to direct cellular damage caused by free oxygen radicals (17). In accordance with this study, an increase in the number of apoptotic cells subsequent to the renal I/R injury was observed in our investigation; however, this increase was prevented by quercetin treatment and this was due to the anti-apoptotic effect of quercetin.

The p53 protein, which stimulates apoptosis, is a guardian of the genome and is expressed in the presence of DNA damage. Therefore, the expression of p53 in tissues reveals an exposure to genotoxic stress, including radiation, chemical agents and ischemia (21). In the present study, we clearly detected the expression of p53 in the I/R group, and this expression decreased in the case of quercetin administration prior to I/R stress, which suggests that quercetin has a protective effect on DNA damage. In addition to this decrease in the level of apoptosis, the cell number increased in the I/R group, suggesting that quercetin also has a protective effect on cell injury and abnormal cell formation.

Renal I/R activates NOS and increases the expression of NOS proteins $(22,23)$. In spite of all the studies carried out, the role of NO in I/R remains controversial. Several studies have indicated that NO induces cellular cytotoxicity and tissue injury via lipid peroxidation, as well as DNA damage 
and pro-apoptotic effects in I/R injury $(12,16,24)$. Conversely, there are studies which demonstrate that the increased activity of NOS is associated with reduced I/R-induced injury (25). Alterations in the expression of various NOS isoforms have been described in renal I/R injury (17). Vinas et al reported that, according to quantitative analysis, $\mathrm{I} / \mathrm{R}$ increased the renal expression of iNOS compared to the control and that no differences were found between $\mathrm{I} / \mathrm{R}$ and the various selective NOS inhibitors (17). In the present study, quantitative iNOS expression increased in the $\mathrm{I} / \mathrm{R}$ group and no significant difference was observed between the I/R and quercetin treatment groups, similar to the Vinas et al study. Immunohistochemical analysis revealed higher eNOS expression in the I/R group; however, this was lower with quercetin treatment.

Within the experimental studies that have been carried out to date, we are unable to identify a study simultaneously investigating the effects of quercetin on apoptosis, p53, NF- $\mathrm{kB}$ and NOS gene expression in renal I/R injury. The results of the present study reveal that quercetin treatment in I/R-injured rat renal tissue reduces the injury by decreasing oxidative stress, apoptosis and $\mathrm{p} 53, \mathrm{NF}-\mathrm{kB}$ and eNOS gene expressions.

In conclusion, quercetin not only has antioxidant and anti-apoptotic activities, but also an inhibitory effect on eNOS and NF- $\kappa B$ for renal tissue protection during I/R injury in rats. Therefore, quercetin may be used to protect renal tissue in $I / R$ injury, which may develop during surgical procedures.

\section{References}

1. Shingu C, Koga H, Hagiwara S, Matsumoto S, Goto K, Yokoi I and Noguchi T: Hydrogen-rich saline solution attenuates renal ischemia-reperfusion injury. J Anesth 24: 569-574, 2010.

2. Elahi MM, Kong YX and Matata BM: Oxidative stress as a mediator of cardiovascular disease. Oxid Med Cell Longev 2 : 259-269, 2009

3. Kacmaz A, Polat A, User Y, Tilki M, Ozkan S and Sener G: Octreotide: a new approach to the management of acute abdominal hypertension. Peptides 24: 1381-1386, 2003.

4. Sahna E, Parlakpinar H, Turkoz Y and Acet A: Protective effects of melatonin on myocardial ischemia-reperfusion induced infarct size and oxidative changes. Physiol Res 54: 491-495, 2005.

5. Jakesevic M, Aaby K, Borge G, Jeppsson B, Ahrne S and Molin G: Antioxidative protection of dietary bilberry, chokeberry and Lactobacillus plantarum HEAL19 in mice subjected to intestinal oxidative stress by ischemia-reperfusion. BMC Complement Altern Med 11: 1-12, 2011.

6. Seok YM, Kim J, Park MJ, Boo YC and Park YK: Wen-pitang-Hab-Wu-ling-san attenuates kidney fibrosis induced by ischemia/reperfusion in mice. Phytother Res 22: 1057-1063, 2008.

7. Boyle EM, Canty TG, Morgan EN, Yun W, Pohlman TH and Verrier ED: Treating myocardial ischemia-reperfusion injury by targeting endothelial cell transcription. Ann Thorac Surg 68 1949-1953, 1999.
8. Kucuk A, Kabadere S, Tosun M, Koken T, Kinaci MK, Isikli B and Erkasap N: Protective effects of doxycycline in ischemia/ reperfusion injury on kidney. J Physiol Biochem 65: 183-191, 2009.

9. Shultz DR, William J and Harrington JR: Apoptosis: programmed cell death at a molecular level. Semin Arthritis Rheum 32: 345-369, 2003.

10. Tosun M, Tosun E, Kalkan S and Avunduk MC: p53 expression between 13-27 weeks old human male fetus gonads. J Mol Histol 38: 271-274, 2007.

11. Balint É and Vousden KH: Activation and activities of the p53 tumor suppressor protein. Br J Cancer 85: 1813-1823, 2001.

12. Lopez-NeblinaA F, Paez AJ, Toledo AH and Toledo-Pereyra LH: Role of nitric oxide in ischemia/reperfusion of the rat kidney. Circ Shock 44: 91-95, 1995.

13. Goligorsky MS, Brodsky SV and Noiri E: Nitric oxide in acute renal failure: NOS versus NOS. Kidney Int 61: 855-861, 2002.

14. Lopez-Marti J, Sola A, Pi F, Alfaro V, Marco A and Hotter G: Nucleotides modulate renal ischaemia-reperfusion injury by different effects on nitric oxide and superoxide. Clin Exp Pharmacol Physiol 30: 242-248, 2003.

15. Sola A, Alfaro V, Vinas JL and Hotter G: Exogenous adenosine enhances caspase-3 activity in warm renal ischaemia. Pflugers Arch 447: 387-391, 2004

16. Wan LL, Xia J, Ye D, Liu J, Chen J and Wang G: Effects of quercetin on gene and protein expression on NOX and NOS after myocardial ischemia and reperfusion in rabbit. Cardiovasc Ther 27: 28-33, 2009.

17. Vinas JL, Sola A, Genseca M, Alfaro V, Pi F and Hotter G: $\mathrm{NO}$ and NOS isoforms in the development of apoptosis in renal ischemia/reperfusion. Free Radic Biol Med 40: 992-1003, 2006.

18. Sobajima S, Shimer AL, Chadderdon RC, et al: Quantitative analysis of gene expression in a rabbit model of intervertebral disc degeneration by real-time polymerase chain reaction. Spine J 5: 14-23, 2005.

19. Kahraman A, Erkasap N, Serteser M and Koken T: Protective effect of quercetin on renal ischemia/reperfusion injury in rat. J Nephrol 16: 219-224, 2003.

20. Spandou E, Tsouchnikas I, Karkavelas G, Dounousi E, Simeonidou C, Guiba-Tziampiri $\mathrm{O}$ and Tsakiris D: Erythropoietin attenuates renal injury in experimental acute renal failure ischaemic/reperfusion model. Nephrol Dial Transplant 21: 330-336, 2006

21. Arikan Y, Tosun M, Yilmaz S, Saykol V and Soylemez Z: The comparative effects of pneumoperitoneum on apoptosis and p53 expression in gastrointestinal organs. J Laparoendosc Adv Surg Tech A 18: 365-713, 2008.

22. Goldberg DM, Hanh SE and Parkes JG: Beyond alcohol: beverage consumption and cardiovascular mortality. Clin Chim Acta 237: 155-187, 1995.

23. Morales AI, Vicente-Sanchez C and Jerkic M: Effect of quercetin on metallothionein, nitric oxide synthases and cyclooxygenase-2 expression on experimental chronic cadmium nephrotoxicity in rats. Toxicol Appl Pharmacol 210: 128-135, 2006.

24. Martinez-Florez S, Gutierrez MB and Sanchez-Campos S: Quercetin prevents nitric oxide production and nuclear factor kappa B activation in interleukin-1 beta activated rat hepatocytes. J Nutr 135: 1359-1365, 2005.

25. Chen H, Xing B, Liu X, Zhan B and Zhou J: Ozone oxidative preconditioning protects the rat kidney from reperfusion injury: the role of nitric oxide. J Surg Res 149: 287-295, 2008. 